\title{
Study of the Angular Positioning of a Rotating Object with Fuzzy Control by State Feedback
}

\author{
CONSTANTIN VOLOŞENCU \\ Department of Automation and Applied Informatics \\ "Politehnica" University of Timişoara \\ Timişoara, 300223, \\ ROMANIA
}

\begin{abstract}
The study in the paper is placed in the broad context of research for increasing the efficiency of motion control. The purpose of the paper is to make a comparative analysis of the state feedback fuzzy control with the linear control for angular positioning of mechanical parts. The structure of the fuzzy control system and its design is presented. Transient characteristics obtained are compared from the point of view of their control efficiency criteria. The differences in performance criteria between the control methods studied are small.
\end{abstract}

KeyWords: Motion control, linear control, state feedback control, fuzzy control.

Received: April 30, 2021. Revised: October 5, 2021. Accepted: October 17, 2021. Published: October $27,2021$.

\section{Introduction}

The paper presents the results of a research study in the field of motion control applied to positioning of an heavy object, with known moment of inertia, in the rotational motion around an axis. The paper includes examples of modeling, control, and optimization in order to increase precision and to reduce the response time. The purpose of the work is the analysis of methods for positioning based on state feedback fuzzy control, compared with the linear control methods. The significance of the study is that it shows the efficiency of these methods, compared to each other. In the literature there is an extremely large number of papers that address the issue of position adjustment, using various adjustment techniques. Several recent papers may be cited, as follows, to show the current state of the literature in the field. An example of position control of a vehicle subjected to unknown conditions using sliding mode and optimal control is presented in [1]. In [2] a study on the optimization of motion control in automatic machines, robots and multi-body systems is presented. In [3] some examples of the application of intelligent control techniques in motion control are presented. Some controversial and diverging hypotheses are considered. Conventional position control is done using as execution elements electric machines, driven by cascade control systems, with internal current control loop, over which overlap a speed control loop and an external position control loop. This is the natural control way. The current and speed control loops must respond as quickly as possible. And the control of the position must be done asymptotically and aperiodically. In this paper, a heavy weight is taken into consideration. Fuzzy logic may bring human reasoning in control. The paper presents, in section 2, preliminary information related to linear and digital position control, the mathematical model of positioning process, transient characteristics and performance criteria. The third section presents the position control method based on state feedback fuzzy control. A set of 27 fuzzy reasoning control rules has been developed and implemented in the fuzzy control in a numerical manner. The fuzzy variables, the rule base, the membership functions, the inference method, and defuzzification method were chosen. The methods were modeled and simulated in Matlab/Simulink. The results that can be obtained with these method are presented in section 4 .
The characteristics obtained by simulations are compared, analyzed, and discussed in section 5. The main contribution of the paper can be summarized as a comparative analysis of four position control methods: conventional linear control, digital control, linear state feedback control and fuzzy control by state feedback, with application in the particular case of a heavy object in rotating motion at variable angular positions. The behaviors of the system for each of these four methods are analyzed. The results are compared with those obtained in the case of linear control. The analyzed methods ensure good performance criteria: zero control error, reduced response time and zero overshoot. The performance criteria differences between the control methods are small.

\section{Preliminaries}

\subsection{Motion Process}

It is considered to adjust the position $\theta$ of the material point with the moment of inertia $J$ in the rotational motion with angular velocity $\omega$. The rotational movement takes place in the presence of friction. The equations of motion of the material point are:

$$
\begin{aligned}
& J \frac{d \omega}{d t}=M-k_{f} \omega \\
& \frac{d \theta}{d t}=\omega
\end{aligned}
$$

where $M$ is mechanical torque and $k_{\mathrm{f}}$ is coefficient of friction.

A speed sensor is used, considered as a first-order delay element with a time constant $T_{\mathrm{T} \omega}$.

The values of the parameters considered are: $J=450$ $\mathrm{kg} \cdot \mathrm{m}^{2}, k_{\mathrm{f}}=120 \mathrm{~kg} \cdot \mathrm{m}^{2} / \mathrm{s}$ and $T_{\mathrm{T} \omega}=0.12 \mathrm{~s}$.

In the dimensioning of control system, the limitations imposed by the actuator must be taken into account, namely the maximum power $P_{\mathrm{m}}$ and the maximum torque $M_{\mathrm{m}}$ that it can develop in permanent working regime.

$$
P \in\left[0, P_{m}\right], M \in\left[-M_{m}, M_{m}\right]
$$

The maximum rotational speed $\omega_{\mathrm{m}}$, which cannot be exceeded by the moving body, must also be taken into account to ensure safe operation. These limitations are introduced in the structure of control system. It is considered that the rotation of the body can take place in both directions of 
rotation. The maximum limit of the position it can reach is $\theta_{\mathrm{m}}$, in one direction or another.

$$
\omega \in\left[-\omega_{m}, \omega_{m}\right], \theta \in\left[-\theta_{m}, \theta_{m}\right]
$$

In this case, the following maximum values were chosen: $M_{\mathrm{m}}=1000 \mathrm{Nm}, \omega_{\mathrm{m}}=0.4 \mathrm{rad} / \mathrm{s}$ and $\theta_{\mathrm{m}}=180^{\circ}$.

\subsection{Linear Control System}

A closed-loop, the basic cascading position control system is selected, as the reference control system. In this system, the speed in the inner loop and the position in the outer loop are adjusted. This mode of adjustment is the natural one. The internal speed control loop must respond faster. The position control loop must have an asymptotic aperiodic behavior. It is considered that the process has a high mechanical time constant $J / k_{\mathrm{f}}$ and a small time constant $T_{\mathrm{T} \omega}$ that of the sensor, and its model is approximated with a transfer function:

$$
\omega_{m}(s) \approx \frac{1}{J s\left(T_{T \omega} s+1\right)} M(s)
$$

Taking into account this model, the speed controller is dimensioned with the symmetric criterion in Kessler's variant [4], which recommends a PI speed controller:

$$
H_{R \omega}(s)=K_{R \omega}\left(1+\frac{1}{T_{R \omega} s}\right)
$$

where:

$$
\begin{aligned}
& K_{R \omega}=\frac{J}{2 T_{T \omega}}=1.875 \\
& T_{R \omega}=4 . T_{T \omega}=0.48
\end{aligned}
$$

This design ensures a speed overshhot $\sigma_{1 \omega} \%=43.5 \%$.

The block diagram of the speed control system is shown in Fig. 1,

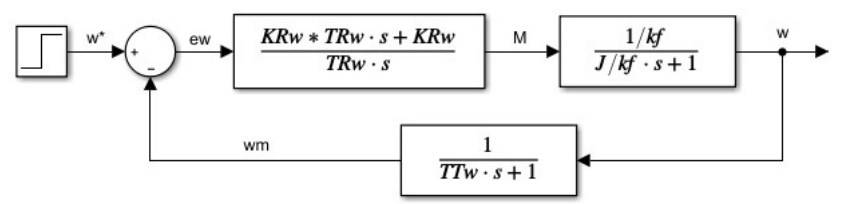

Fig. 1 Linear speed control system.

where $\omega$ is denoted with $w$.

The unit step response of the linear speed control system is shown in Fig. 2. It is observed that the speed settling time is short, of the order of 1.5 seconds, compared to the large mass in motion.

Since the controlled process has a purely integrative character, a position regulator of proportional type is chosen, with gain coefficient $K_{\mathrm{R} \theta}=0.8$. The block diagram of the position linear control system is shown in Fig. 3, where $\theta$ is denoted with $\mathrm{p}$. The unit step response of the position control system is shown in Fig. 4 and the speed characteristic is presented in Fig. 5. It is observed that the position settling time is short, of the order of 6 seconds, compared to the high moment of inertia of object in motion. So, the mass rotates at an angle of $57.2^{\circ}$ in 6 seconds.

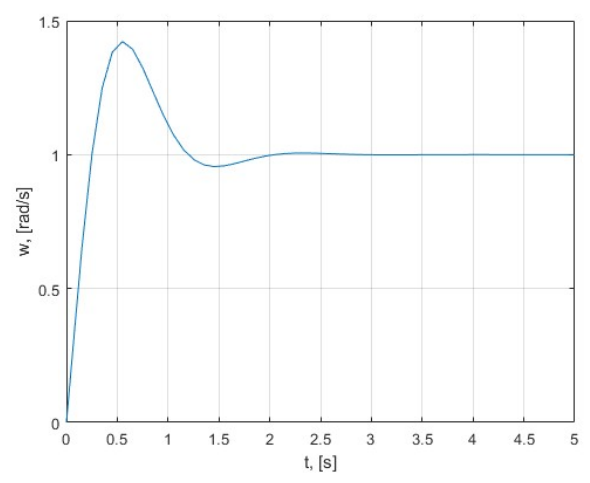

Fig. 2 Linear control system speed characteristic.

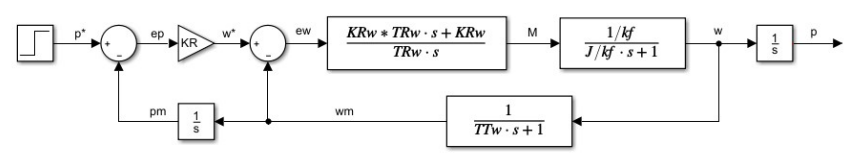

Fig. 3 Linear position control system.

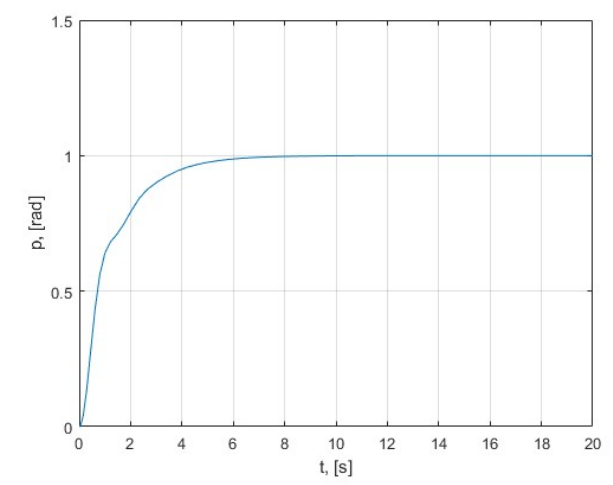

Fig. 4 The unit step response of the position control system.

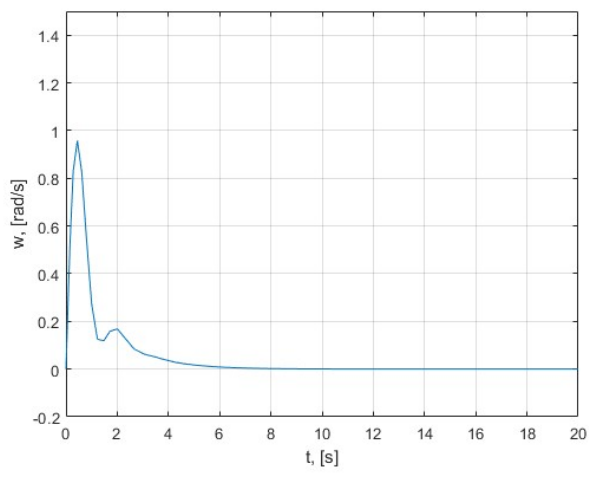

Fig. 5 Speed characteristic.

\subsection{Digital Control System}

Due to the fact that the implementation of regulators is done digitally, an example of implementation in discrete time of the conventional position control system is presented below. The speed controller is approximated with the trapezoid method:

$s=\frac{2}{h} \frac{z-1}{z+1}$

and its function in $z$ results: 
$H_{R \omega}(z)=K_{R \omega} \frac{\left(1+\frac{h}{2 T_{R \omega}}\right) z-\left(1-\frac{h}{2 T_{R \omega}}\right)}{z-1}$

The sampling period $h$ is chosen to be much shorter than the shortest time constant $\mathrm{T}_{\mathrm{T} \omega}: h=0.001 \mathrm{~s}$.

The numerical algorithm for implementing the speed controller is:

$M_{k+1}^{*}=M_{k}^{*}+a_{1} e_{\omega k+1}+a_{2} e_{\omega k}$

where $M_{\mathrm{k}}^{*}$ is the torque reference at moment $t_{\mathrm{k}}=k . h, e_{\omega \mathrm{k}}$ is the speed error at moment $t_{\mathrm{k}}$ and $a_{1}=1877$, and $a_{2}=-1873$ are two coefficients.

The speed controller may be implemented digitally, using a simple microcontroller, with two multiplication and two summation operations and memorizing reference torque and error values at times $t_{\mathrm{k}}$ and $t_{\mathrm{k}+1}$.

The block diagram of the numerical speed control system is shown in Fig. 6.

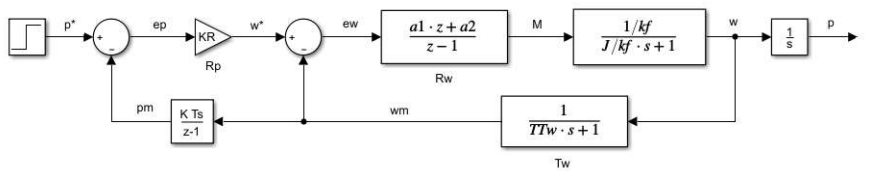

Fig. 6 Numerical position control system.

The characteristics of position and speed, in response to the step signal, for the discrete time system, are identical to those of the system in continuous time. This fact demonstrates that the dimensioning of the speed controller in discrete time, by approximation with the trapezoid method, starting from the values of the coefficients of the controller in continuous time, was correct.

A closer to reality modeling of the control system includes speed, torque and position limitations, as in Fig. 7.

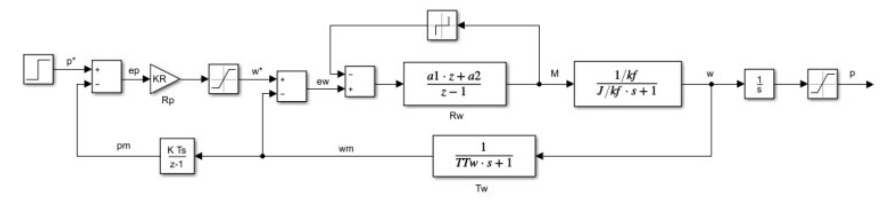

Fig. 7 Numerical position control system with limitations.

In the control structure from Fig. 7 an anti-wind-up circuit has been introduced, in parallel with the speed control, which also ensures the limitation of the prescribed torque. A prescribed speed limit and position limit have also been introduced.

The unit step responses of the following variables of digital position control system with limitations: speed reference, torque, speed, position are shown in Fig. 8, 9, 10 and 11 respectivelly.

Analysing these characteristics the following observations arise. The speed reference is limited at $0.3 \mathrm{rad} / \mathrm{s}$, which leads to a decrease in control torque at start. A lower torque results in a longer response time. It is observed that the position settling time is still short, of the order of 8 seconds, compared to the high moment of inertia of object in motion. On the speed characteristic it is observed the speed is not limited at start, but it is limited in a permanent functioning regime.

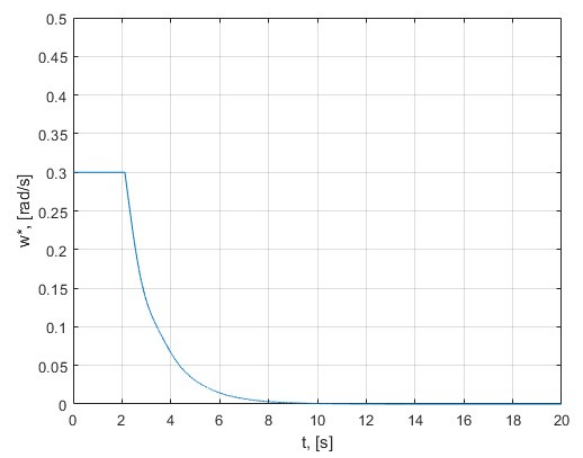

Fig. 8 Speed reference.

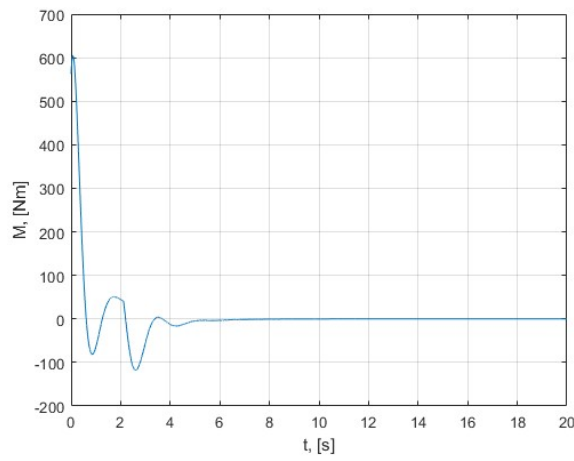

Fig. 9 Torque characteristic.

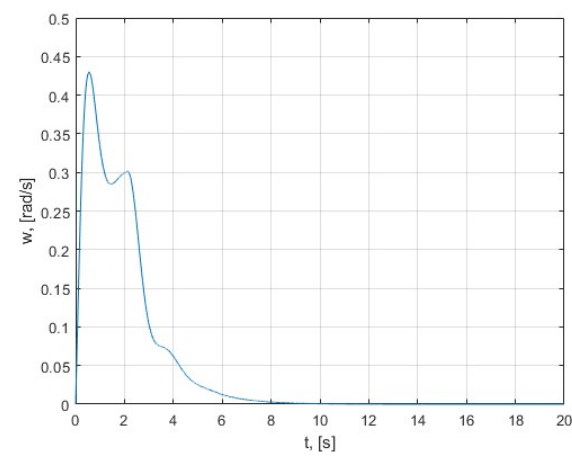

Fig. 10 Speed characteristic.

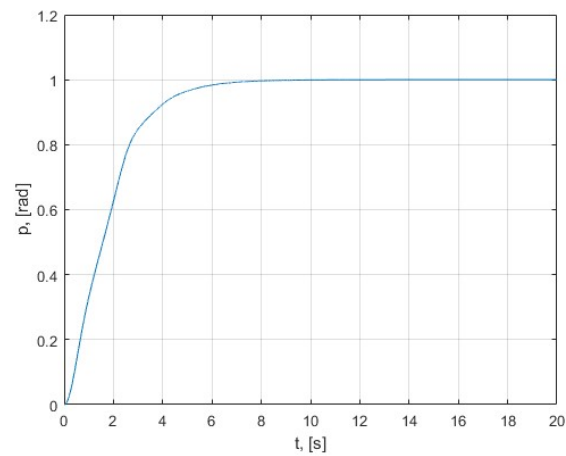

Fig. 11 Position characteristic.

So, the object rotates at an angle of $57.2^{\circ}$ in 8 seconds, with limitation in command power. The simulation of linear control system is made considering an infinite command power. In reality, the command has finite power, which leads to a longer response time. 


\subsection{State Feedback Control}

As a preliminary treatment for fuzzy control, the state feedback control is analyzed [5]. The structure of the position state feedback control system is presented in Fig. 12.

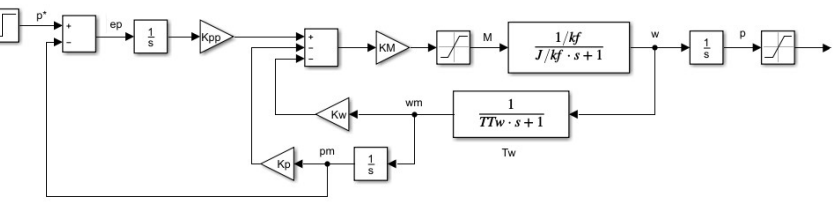

Fig. 12 Position state feedback control system with limitations.

The state equations of systems are:

$$
\begin{aligned}
& \frac{d \omega}{d t}=-\frac{k_{f}}{J} \omega+\frac{1}{J} M \\
& \frac{d \theta}{d t}=\omega \\
& \frac{d e_{\theta i}}{d t}=\theta^{*}-\theta
\end{aligned}
$$

where

$$
A=\left[\begin{array}{ccc}
-\frac{k_{f}}{J} & 0 & 0 \\
1 & 0 & 0 \\
0 & -1 & 0
\end{array}\right], b=\left[\begin{array}{l}
\frac{1}{J} \\
0 \\
0
\end{array}\right], b_{r}=\left[\begin{array}{l}
0 \\
0 \\
1
\end{array}\right], c=\left[\begin{array}{lll}
0 & 1 & 0
\end{array}\right]
$$

and the command low is:

$$
M=K_{M}\left(K_{\theta p} e_{c i}-K_{\omega} \omega-K_{\theta} \theta\right)
$$

It can be seen that a third state variable $\mathrm{e}_{\theta \mathrm{i}}$ was introduced, at the output of an integrator block, on the path of the position error. This leads to zero steady-state error:

$$
\lim _{t \rightarrow \infty} e_{\theta}(t)=0
$$

The controllability matrix is calculated:

$$
M_{c}=\left[\begin{array}{lll}
b & A b & A^{2} b
\end{array}\right]
$$

The poles of the closed loop control system are imposed such that the control efficiency criteria to be ensured: overshoot $\sigma_{1} \%=0$ and a small response time. The characteristic polynomial $\mu(s)$ is calculated. The state feedback vector $f$ is determined:

$$
f=-m_{c 3} \mu(A)
$$

where $m_{\mathrm{c} 3}$ is the third line of controllability matrix. And

$$
f=K_{M}\left\lfloor\begin{array}{lll}
K_{\omega} & K_{\theta} & K_{\theta p}
\end{array}\right\rfloor
$$

The values obtained for the feedback coefficients are: $K_{\mathrm{M}}$ $=800, K_{\theta}=15, K_{\theta \mathrm{p}}=10$ and $K_{\omega}=5$.

The unit step responses of the following variables of state feedback control system with limitations: speed reference, torque, speed, position are shown in Fig. 13, 14, 15 and 16 respectivelly. It can be seen the torque and speed are limited. The response time is shorter than in the case of error control system.

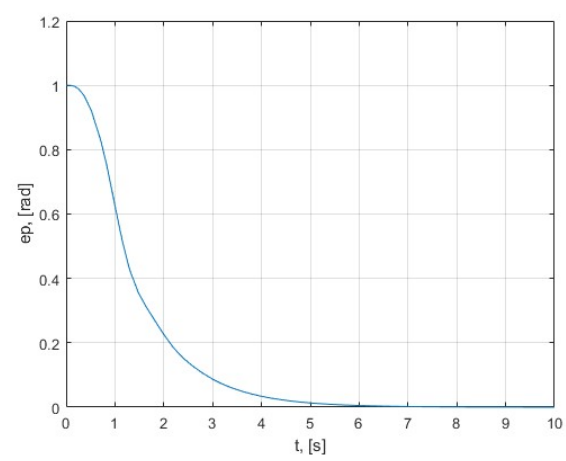

Fig. 13 Position error characteristic.

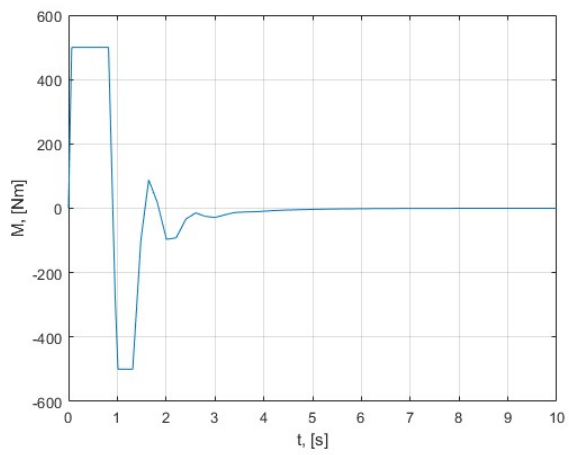

Fig. 14 Torque characteristic.

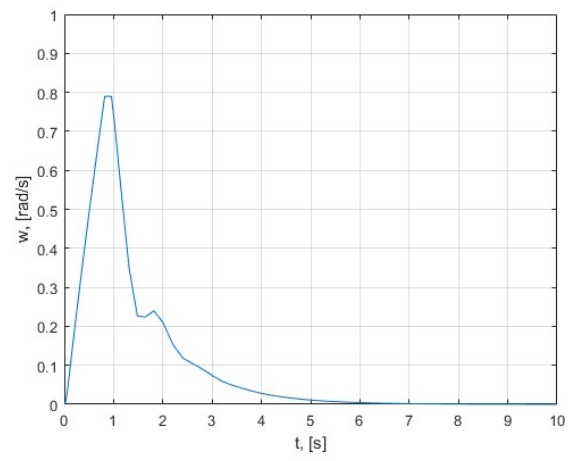

Fig. 15 Speed characteristic.

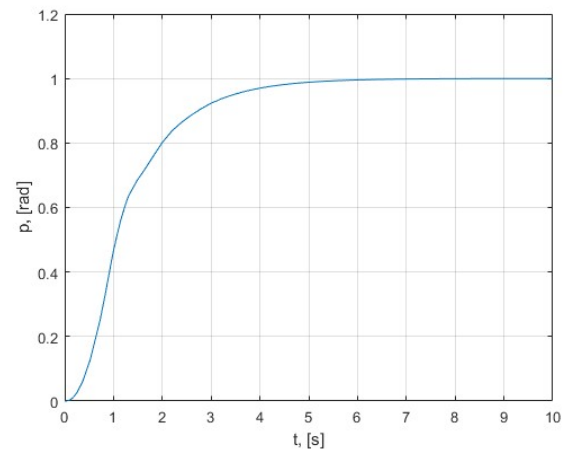

Fig. 15 Position characteristic.

\section{Fuzzy Control System}

According to the theory in [6] the fuzzy control system can be assimilated to the state feedback control system. Physical state variables $e_{\theta}, d \omega / \mathrm{dt}$ and $\omega$ become input variables of fuzzy controller, where $e_{\theta}=\theta^{*}-\theta$. The torque $M$ is the 
output variable of fuzzy controller. The universes of discourse of the fuzzy variables are:

$$
M \in\left[-M_{m}, M_{m}\right], \omega \in\left[-\omega_{m}, \omega_{m}\right], \theta \in\left[-\theta_{m}, \theta_{m}\right]
$$

where $M_{\mathrm{m}}=1000 \mathrm{Nm}, \omega_{\mathrm{m}}=0.3 \mathrm{rad} / \mathrm{s}$ and $\theta_{\mathrm{m}}=\pi$.

The fuzzy controller is designed based on previous experimentals $[7,8,9]$.

Mamdani's structure is chosen for fuzzy block.

The membership functions chosen for the fuzzy variables are presented in Fig. 16.

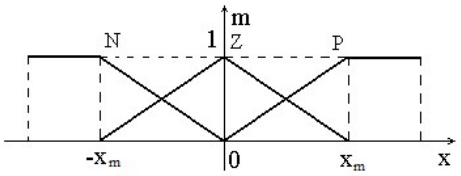

Fig. 16 Position characteristic.

where $\mathrm{x}$ symbolizes the above physical variables and $\mathrm{xm}$ their maximum values.

The rule base has 27 rules, resulting from the reasoning of working with the process. It is presented in Table 1.

Table 1. The rule base
\begin{tabular}{|c|c|c|c|}
\hline$e_{\theta}$ & $d \omega / \mathrm{dt}$ & $\omega$ & $M$ \\
\hline $\mathrm{Z}$ & $\mathrm{Z}$ & $\mathrm{Z}$ & $\mathrm{Z}$ \\
\hline $\mathrm{Z}$ & $\mathrm{Z}$ & $\mathrm{N}$ & $\mathrm{P}$ \\
\hline $\mathrm{Z}$ & $\mathrm{Z}$ & $\mathrm{P}$ & $\mathrm{N}$ \\
\hline $\mathrm{Z}$ & $\mathrm{N}$ & $\mathrm{Z}$ & $\mathrm{P}$ \\
\hline $\mathrm{Z}$ & $\mathrm{N}$ & $\mathrm{N}$ & $\mathrm{P}$ \\
\hline $\mathrm{Z}$ & $\mathrm{N}$ & $\mathrm{P}$ & $\mathrm{Z}$ \\
\hline $\mathrm{Z}$ & $\mathrm{P}$ & $\mathrm{Z}$ & $\mathrm{N}$ \\
\hline $\mathrm{Z}$ & $\mathrm{P}$ & $\mathrm{N}$ & $\mathrm{Z}$ \\
\hline $\mathrm{Z}$ & $\mathrm{P}$ & $\mathrm{P}$ & $\mathrm{N}$ \\
\hline $\mathrm{N}$ & $\mathrm{Z}$ & $\mathrm{Z}$ & $\mathrm{N}$ \\
\hline $\mathrm{N}$ & $\mathrm{Z}$ & $\mathrm{N}$ & $\mathrm{N}$ \\
\hline $\mathrm{N}$ & $\mathrm{Z}$ & $\mathrm{P}$ & $\mathrm{N}$ \\
\hline $\mathrm{N}$ & $\mathrm{N}$ & $\mathrm{Z}$ & $\mathrm{N}$ \\
\hline $\mathrm{N}$ & $\mathrm{N}$ & $\mathrm{N}$ & $\mathrm{Z}$ \\
\hline $\mathrm{N}$ & $\mathrm{N}$ & $\mathrm{P}$ & $\mathrm{N}$ \\
\hline $\mathrm{N}$ & $\mathrm{P}$ & $\mathrm{Z}$ & $\mathrm{N}$ \\
\hline $\mathrm{N}$ & $\mathrm{P}$ & $\mathrm{N}$ & $\mathrm{N}$ \\
\hline $\mathrm{N}$ & $\mathrm{P}$ & $\mathrm{P}$ & $\mathrm{N}$ \\
\hline $\mathrm{P}$ & $\mathrm{Z}$ & $\mathrm{Z}$ & $\mathrm{P}$ \\
\hline $\mathrm{P}$ & $\mathrm{Z}$ & $\mathrm{N}$ & $\mathrm{P}$ \\
\hline $\mathrm{P}$ & $\mathrm{Z}$ & $\mathrm{P}$ & $\mathrm{P}$ \\
\hline $\mathrm{P}$ & $\mathrm{N}$ & $\mathrm{Z}$ & $\mathrm{P}$ \\
\hline $\mathrm{P}$ & $\mathrm{N}$ & $\mathrm{N}$ & $\mathrm{P}$ \\
\hline $\mathrm{P}$ & $\mathrm{N}$ & $\mathrm{P}$ & $\mathrm{P}$ \\
\hline $\mathrm{P}$ & $\mathrm{P}$ & $\mathrm{Z}$ & $\mathrm{P}$ \\
\hline $\mathrm{P}$ & $\mathrm{P}$ & $\mathrm{N}$ & $\mathrm{P}$ \\
\hline $\mathrm{P}$ & $\mathrm{P}$ & $\mathrm{P}$ & $\mathrm{Z}$ \\
\hline
\end{tabular}

Some examples of fuzzy reasoning on which the rule base was built are given below.

- If $e_{\theta}$ is zero and $d \omega / \mathrm{dt}$ is zero and $\omega$ is zero then $M$ is zero;

- If $e_{\theta}$ is negative and $d \omega / \mathrm{dt}$ is zero and $\omega$ is zero then $M$ is negative;

- If $e_{\theta}$ is positive and $d \omega / \mathrm{dt}$ is positive and $\omega$ is positive then $M$ is zero.

The firing rules are presented in Fig. 17.
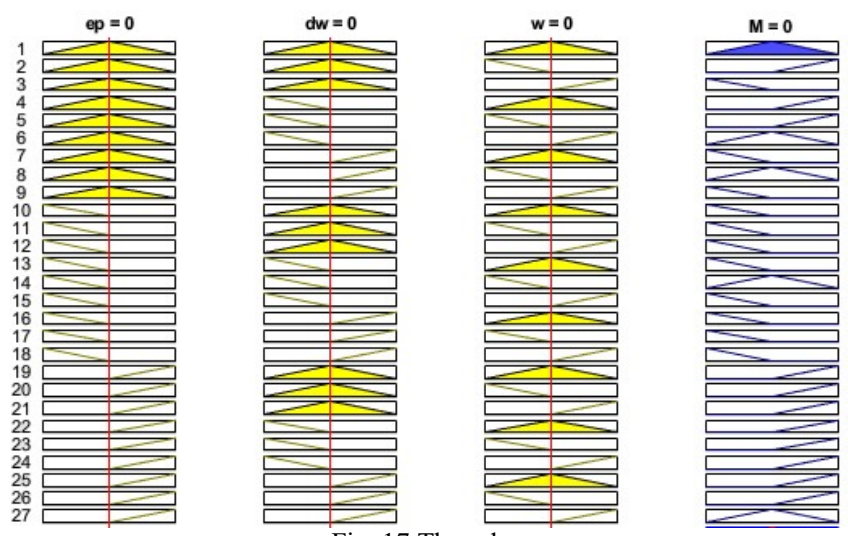

Fig. 17 The rules.

The inference is min-max and defuzzification is with the centre of gravity. The use of only three fuzzy values and the min-max inference ensures the strongest nonlinear character at the fuzzy controller $[7,8,9]$.

The surfaces of the input-output characteristics of the fuzzy block are presented in Figs. 18, 19 and 20.

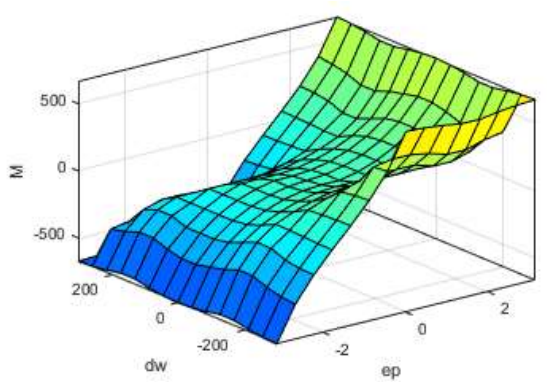

Fig. 18 Surface $M=f\left(e_{\theta}, d \omega\right)$.

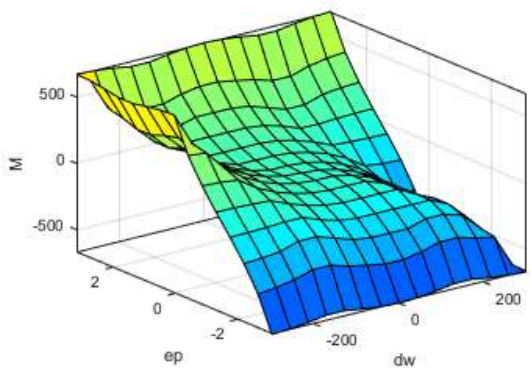

Fig. 19 Surface $M=f\left(e_{\theta}, \omega\right)$.

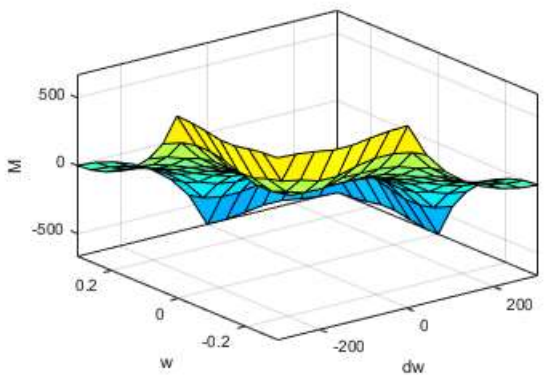

Fig. 20 Surface $M=f(d \omega, \omega)$.

The structure of the fuzzy control system is presented in Fig. 21. It is a state feedback fuzzy control system.

The stucture of the fuzzy controller is presented in Fig. 22 


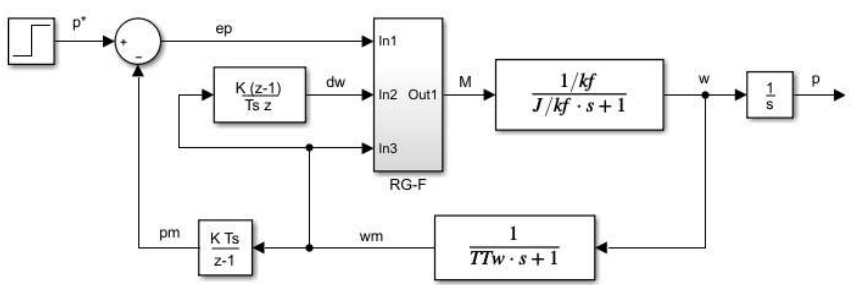

Fig. 21 Fuzzy control system.

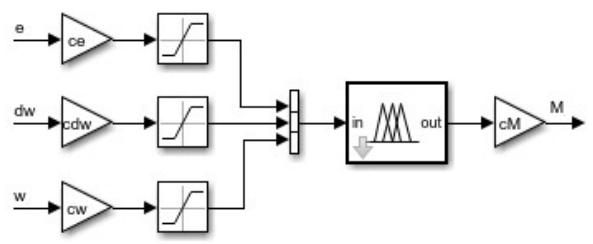

Fig. 22 Fuzzy controller.

The fuzzy controller has three inputs. Each input is limited at its maximum value. The fuzzy bloc is implented using the fuzzy logic designer from Matlab. It has Mamdani's structure characteristics presented above.

The dynamic behavior of the fuzzy control system is adjusted with the coefficients $c_{\mathrm{e}}, c_{\mathrm{dw}}, c_{\mathrm{w}}$ and $c_{\mathrm{M}}$.

The characteristics obtained by simulation for the variables: position error $e_{\theta}$, torque $M$, rotation speed $\omega$ and position $\theta$, from the fuzzy control system, are presented respectively in Figs. 23, 24, 25 and 26.

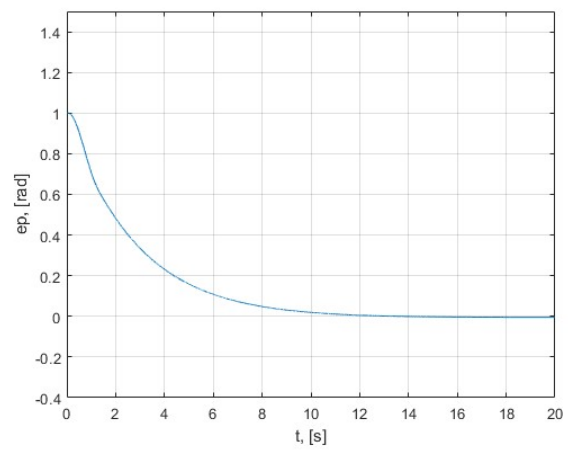

Fig. 23 Position error.

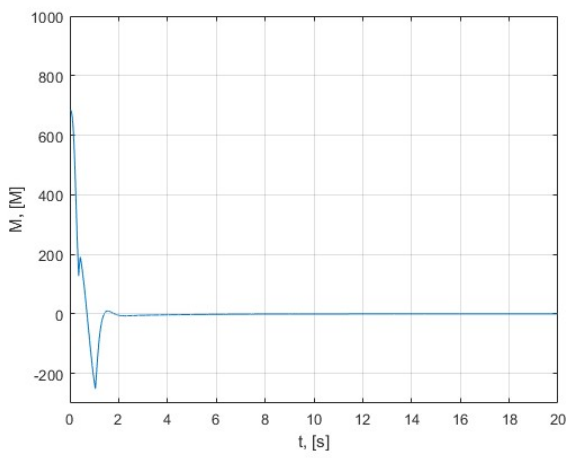

Fig. 24 Torque

Analyzing the obtained characteristics it can be said that with the help of a fuzzy control system a behavior similar to the linear state control system can be obtained: a zero error in steady state and an asymptotic, aperiodic variation of position.

Regarding the stability of the fuzzy control system, the following statement may be done. Based on the demonstration in $[8,9]$, it can be said that due to the fact that the response to the system output to a bounded input signal, it is in turn bounded, the system is externally stable, corresponding to BIBO stability - bounded input - bounded output.

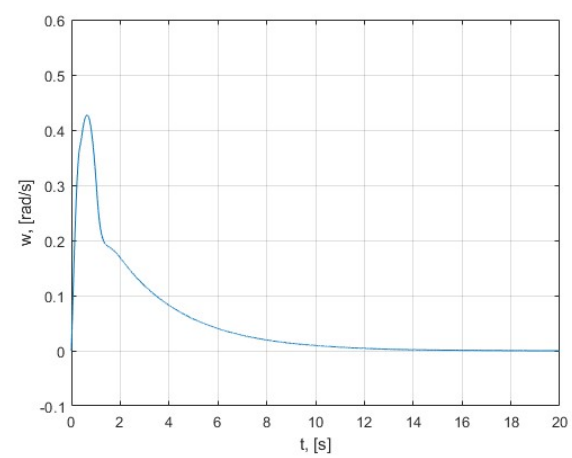

Fig. 25 Speed.

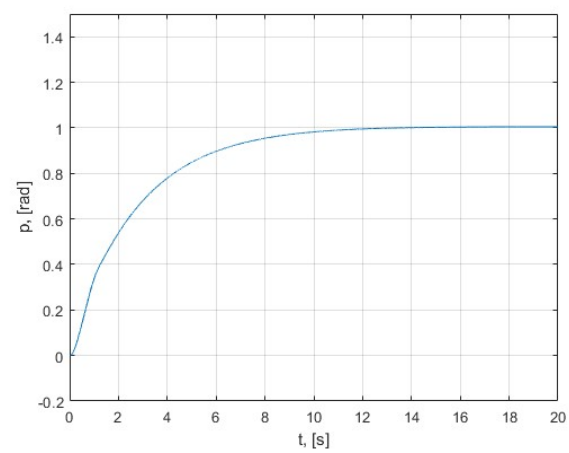

Fig. 26 Position.

\section{Conclusions}

The paper makes a presentation of results obtained with some angular position control structures: linear control with error feedback, digital control system with limitation, linear state feedback control system and state feedback fuzzy control system.

The design method of the fuzzy control is presented.

Their transient responses at unity input signal are presented, analyzed and compared.

The control systems analyzed have good control performance criteria: small settling time, compared to the high moment of inertia and zero overshoot.

The differences between the efficiency criteria of four control structures are small.

\section{References}

[1] M.T. Vu, T.H. Le, H.J.N.N. Thanh, T.T. Huynh, M. Van, Q.D. Hoang, T.D. Do, "Robust Position Control of an Over-actuated Underwater Vehicle under Model Uncertainties and Ocean Current Effects Using Dynamic Sliding Mode Surface and Optimal Allocation Control", Sensors, vol. 21, no. 3, 747, Jan. 2021.

[2] D. Richiedei, P. Boscariol, (Eds.) Optimization of Motion Planning and Control for Automatic Machines, Robots and Multibody Systems, MDPI, 2020.

[3] M. Čech, A.J. Beltman, K. Ozols. 2021. "Pushing Mechatronic Applications to the Limits via Smart Motion Control" Applied Sciences, vol. 11 , no. 18, 8337, September 2021.

[4] C. Kessler, "Das symmetrische optimum", Regelungstechnik, no. 6, pp. 395-400 and 432-436, 1958. 
[5] G.F. Franklin, J.D. Powell, A.E. Naeini, Feedback Control of Dynamic Systems, Global Edition, Pearson Educational Limited, 2019.

[6] H. Buhler, Reglage par logique floue, Press Polytechniques et Universitaires Romand, Lausane, Switzerland, 1994.

[7] C. Voloșencu, "Reducing Energy Consumption and Increasing the Performances of AC Motor Drives Using Fuzzy PI Speed Controllers", Energies, vol. 14, no. 8, 2083, June 2021.

[8] C. Voloşencu, "Stabilization of Fuzzy Control Systems", WSEAS Transactions on Systems and Control, Vol. 3. Issue 3, pp. 879-896, Oct. 2008.

[9] C. Voloșencu, "A Comparative Analysis of Some Methods for Wind Turbine Maximum Power Point Tracking", Mathematics. 2021; vol. 9, no. 19, 2399, Sept. 2021.

\section{Creative Commons Attribution License 4.0 (Attribution 4.0 International, CC BY 4.0)}

This article is published under the terms of the Creative Commons Attribution License 4.0

https://creativecommons.org/licenses/by/4.0/deed.en US 